\title{
Genitourinary syndrome of menopause: effects on related factors, quality of life, and self-care power
}

\author{
Hediye Karakoç ${ }^{1}$, Arzu Kul Uçtu², Nebahat Özerdoğan ${ }^{3}$ \\ ${ }^{1}$ Department of Midwifery, College of Health Science, KTO Karatay University, Konya, Turkey \\ ${ }^{2}$ Department of Midwifery, College of Health Science, Bozok University, Yozgat, Turkey \\ ${ }^{3}$ Department of Midwifery, Faculty of Health Science, Eskişehir Osmangazi University, Eskişehir, Turkey
}

\begin{abstract}
Introduction: This study aimed to determine the effects of genitourinary syndrome of menopause on related factors, quality of life, and self-care power.

Material and methods: This case-control epidemiological study included 300 postmenopausal women aged 48-60 years who were divided into two groups: the case group (141) with genitourinary syndrome and the control group (159) without genitourinary syndrome. Data were evaluated by chi-square and $t$-tests in independent groups and logistic regression analysis.

Results: The incidence of genitourinary syndrome of menopause was 0.61 times higher in women with a lower educational level than in those with a high educational level, 0.44 times higher in those with chronic disease than in those without, 2.54 times higher in those who continuously used medication than in those who did not, and 2.45 times higher in those with urinary incontinence than in those without. The mean Self-Care Power Scale score was significantly higher in the control group (101.52 \pm 21.50$)$ than in the case group (83.96 $\pm 25.64)$. The mean Menopause-Specific Quality of Life Scale score was significantly higher in the case group $(65.52 \pm 33.47)$ than in the control group $(37.06 \pm 25.81)$.

Conclusions: Low educational level, chronic disease, urinary incontinence, and continuous drug use are associated with genitourinary syndrome of menopause, which negatively affects the quality of life and self-care power in women.
\end{abstract}

Key words: genitourinary syndrome, quality of life, self-care power.

\section{Introduction}

Genitourinary syndrome of menopause (GSM) is characterized by changes in the levels of sex hormones resulting in changes in the labia major/minor, clitoris, vestibule, vagina, urethra, and bladder. The terms vulvovaginal atrophy and atrophic vaginitis have been found to be insufficient to define menopausal symptoms associated with changes in the vulva, vagina, and lower urinary tract due to estrogen deficiency; thus, the term GSM has been developed for a more accurate and inclusive terminology. It provides accurate and comprehensive information about the general postmenopausal status [1].

The genitourinary syndrome that occurs during menopause causes dryness and dyspareunia (the most uncomfortable symptoms reported in clinical studies), staining or bleeding, burning, discomfort, and irritability in many women [1]. Increased vaginal basaliza- tion results in a persistent, malodorous discharge [2]. In their study of the effects of vulvovaginal atrophy in 1000 postmenopausal women, Simon et al. reported that $64 \%$ of women had painful sexual intercourse and loss of libido, and $58 \%$ of women avoided sexual intercourse [3]. Pastore et al. reported that the most common genitourinary symptoms were vaginal dryness (27\%), vaginal irritation or pruritus (18.6\%), vaginal discharge (11.1\%), and dizziness (5.2\%) in a study of women's health [4]. Genitourinary syndrome causes negative vaginal problems as well as frequent emotional distress, leading to adverse effects on the quality of life of women with menopause [5-8].

Genitourinary syndrome of menopause affects approximately $50 \%$ of middle-aged and elderly women $[1,2,9-11]$. With the development of health services, the increase in diagnostic and treatment possibilities has prolonged human life span. According to 2011 data of the Turkey Statistical Institute, the innate life 
expectancy of women in Turkey is 77.1 years, whereas, according to the 2013 TUIK data, it increased to 79.4 years [12-14]. In this case, a woman will spend onethird of her life in the menopausal period on average and even more in the future. The World Health Organization projects that, by 2030, an estimated 1.2 billion women will be over 50 years of age, i.e., menopausal. Understanding menopause and preventing its effects and outcome are the most important tasks to increase the quality of life of women over 50 years of age. Although it is difficult to deal with social and cultural taboos, many believe that health workers should urgently improve the situation. First, it is necessary to investigate the results of GSM to determine the dimensions of the problem, quality of life, and its effects on self-care power [15].

\section{Aim of the study}

The present study was conducted to determine the effects of GSM on related factors, quality of life, and self-care power.

\section{Material and methods \\ Study design and participants}

This case-control epidemiological study was conducted between September 2016 and May 2017 and consisted of women in the postmenopausal period aged 48-60 years who presented to family health centers. The sample size of the study was calculated as 140 women for the case group and 140 postmenopausal women for the control group according to the $\mathrm{G}^{*}$ Power 3.1 .5 program [16]. The case group (141) and the control group (159) included postmenopausal women who met the study criteria in the specified date range and agreed to participate in the study. The case group consisted of women with GSM, whereas the control group consisted of women without GSM.

The Menopausal Symptom Assessment Scale was used to evaluate the case and control groups. The ratings of the urogenital complaints subscale were classified as "mild", "moderate", "severe", or "very severe", and women who provided such ratings were defined as "those living with GSM", while those who did not were defined as "those without genitourinary syndrome". The urogenital complaints subscale of the Menopausal Symptom Assessment Scale is categorized into three aspects: 1) sexual problems (change in sexual desire, sexual relations, and satisfaction), 2) urinary problems (difficulties during urination, frequent urination, incontinence), and 3) vaginal problems (dryness and burning sensation in the vagina and strain on sexual intercourse). The case group of the study included those living with GSM, willing to participate in the study. The control group of the study included those without genitourinary syndrome, similar to the case group in terms of sociodemographic data and willing to participate in the study.

\section{Measures}

The Participant Information Form, Menopausal Symptoms Assessing Scale (MSAS), Menopause-Specific Quality of Life Scale (MSQLS), and Self-Care Power Scale (SCPS) were used for data collection. Data were gathered by face-to-face interviews with women in family health centers.

\section{Participant information form}

This form was prepared by the researchers in accordance with the literature. It contains the following information of women: socio-demographic characteristics (age, body mass index, education, employment status, income status, marital status, satisfaction with marital status, having chronic illness, continuous drug use, and smoking status) and gyneco-obstetric features (number of pregnancies, duration of menopause, gynecologic state of operation, presence of urinary incontinence, causes of urinary incontinence, treatment received, and perception of menopause). Seventeen questions were considered to be related to menopause. Rare incontinence is defined as "incontinence occurring one or more times per month", regular incontinence is defined as "incontinence occurring two or more times per month", and severe incontinence is defined as "incontinence with continuous use of a pad, regardless of frequency" [17].

\section{Menopausal Symptoms Assessing Scale}

Menopausal Symptoms Assessing Scale (MSAS) was developed in Germany by Schneider et al. [18] and was adapted to English in 1996. In Turkey, the translation and adaptation of this scale to Turkish was done by Gürkan [19]. The scale consists of somatic, psychological, and urogenital symptom subdimensions. The Likert-type scale consists of 11 items, with the following options: " 0 = none", " 1 = light", " 2 = medium", " 3 = severe", and " 4 = very severe". The total score of the scale is calculated based on the scores given for each item. The Cronbach's $\alpha$ reliability coefficient was 0.84 . In contrast, the increase in the total score on the scale indicates an increase in the severity of the complaints experienced, indicating that the quality of life is adversely affected [19].

\section{Menopause-Specific Quallity of Life Scale}

Menopause-Specific Quality of Life Scale (MSQLS) was developed by Hilditch et al. [20] and adapted to Turkish by Kharbouch and Şahin [21], and studies of its validity 
and reliability have been conducted. The scale consists of 29 Likert-type items classified into vasomotor, psychosocial, physical, and sexual topics. Women were asked about their complaints in the last month. If the answer was "Yes", the severity of the complaint was scored between 0 and 6 , wherein 0 indicated "did not bother me at all" and 6 indicated "overwhelming" based on the degree of the individual's discomfort. In the analysis, each question item was scored between 1 and 8 points, with 1 point indicating "no problem" and 2 points indicating "presence of problems but not disturbing". Moreover, 3-8 points described the severity of the problem and its increasing relevance. Because the number of questions per topic varied, the average of the scores was evaluated as the overall score of each item. Each question has a total score between 1 and 8; a low score indicates a high quality of life [20].

\section{Self-Care Power Scale}

Self-Care Power Scale (SCPS) was developed by Kearney and Fleisher [22] and was adapted by Nahcivan [23], who conducted validity and reliability studies. The scale consists of 35 Likert-type items, with the following options: "do not define me at all", "agree", "no idea", "define me a little", and "define me greatly". Each expression on the scale is evaluated between 0 and 4 points. Eight self-rated health claims are considered negative. For this reason, scoring is reversed for negative expressions [23].

\section{Statistical analysis}

Data coding and evaluation were performed us ing the SPSS 20.0 package program. Statistical analysis was conducted using descriptive statistics and the chi-square test for comparing percentile data between groups, the independent $t$-test for comparing the mean in normally distributed parametric data, and logistic regression analysis for determining the factors associated with GSM.

\section{Limitations of the study}

The presence of genitourinary syndrome was not determined by physical examination findings.

\section{Results}

When the socio demographic characteristics of the case group were examined, $48.2 \%$ of women were aged 57-60 years, $58.2 \%$ were overweight, $71.6 \%$ were primary school graduates, $90.8 \%$ were unemployed, $66 \%$ perceived income equal to their expenses, $73.8 \%$ were married, $35.5 \%$ were satisfied with marital life, $62.4 \%$ had a chronic disease, $66 \%$ used drugs continuously, and $80.9 \%$ did not use cigarettes. In the control group, $48.4 \%$ of women were aged 57-60 years, $48.4 \%$ were overweight, $60.4 \%$ were primary school graduates, $76.1 \%$ were unemployed, $62.3 \%$ perceived income equal to their expenses, $73 \%$ were married, $40.3 \%$ were satisfied with marital life, $58.5 \%$ had a chronic illness, $68.6 \%$ used drugs continuously, and $73 \%$ did not use cigarettes. On comparing the case and control groups in terms of sociodemographic characteristics, there was a statistically significant relationship between education ( $p \leq 0.001)$, employment status ( $p=0.001)$, income status perception $(p=0.002)$, and marital satisfaction $(p=0.003)$ (Table 1). The proportion of women who were unemployed, had low educational status and low income, and were dissatisfied with their marital life was lower in the GSM case group than in the control group.

When gyneco-obstetric features of women in the case group were examined, $83.7 \%$ had three or more pregnancies, $63.8 \%$ had been in the menopausal period for 4 or more years, $63.1 \%$ did not undergo gynecologic surgery, $31.9 \%$ had no urinary incontinence, and $21.3 \%$ reported urinary incontinence when they felt sudden urination, $87.2 \%$ received no menopause treatment, and $61 \%$ had a negative perception of the menopausal period. In the control group, $79.9 \%$ of women had three or more pregnancies; $73.6 \%$ had been in menopausal period for 4 or more years; $65.4 \%$ did not undergo gynecologic surgery; $68.6 \%$ had no urinary incontinence; $13.2 \%$ reported urinary incontinence during physical activity, laughing, or sneezing; $92.5 \%$ received no menopause treatment; and $56 \%$ had a positive perception of the menopausal period. There was a statistically significant relationship between the case and control groups in terms of gyneco-obstetric characteristics, such as urinary incontinence $(p=0.000)$, and menopausal perception ( $p=0.003$ ) (Table 2 ). The proportion of women who reported severe urinary incontinence when there was a sudden urge to urinate and who perceived menopause as negative was higher in the case group than in the control group.

A comparison of the mean scores of the scales between the case and control groups is presented in Table 3. The mean SCPS score was significantly higher in the control group $(101.52 \pm 21.50)$ than in the case group (83.96 \pm 25.64$)$. However, the mean MSQLS score was significantly higher in the case group $(65.52 \pm 33.47)$ than in the control group $(37.06 \pm 25.81)$. The mean scores of the vasomotor $(p=0.000)$, psychosocial $(p=0.000)$, physical $(p=0.000)$, and sexual $(p=0.000)$ areas were significantly different between the case group and the control group (Table 3 ).

The results of logistic regression analysis to investigate the variables affecting the genitourinary syndrome revealed that the incidence of GSM in less educated women was 0.61 times $(p=0.004)$ higher than that in highly educated women, in women with chronic illness it was 0.44 times $(p=0.042)$ higher than that in those 
Table 1. Comparison of case and control groups in terms of sociodemographic characteristics

\begin{tabular}{|c|c|c|c|}
\hline Sociodemographic characteristics & $\begin{array}{c}\text { Case group } \\
n(\%)\end{array}$ & $\begin{array}{c}\text { Control group } \\
n(\%)\end{array}$ & Significance value \\
\hline \multicolumn{3}{|l|}{ Age group } & \multirow{4}{*}{$\begin{array}{l}\chi^{2}=0.381 \\
p=0.827\end{array}$} \\
\hline $48-51$ & $32(22.7)$ & $40(25.2)$ & \\
\hline $52-56$ & $41(29.1)$ & $42(26.4)$ & \\
\hline $57-60$ & $68(48.2)$ & $77(48.4)$ & \\
\hline \multicolumn{3}{|l|}{ Body mass index $\left(\mathrm{kg} / \mathrm{m}^{2}\right)$} & \multirow{4}{*}{$\begin{array}{l}\chi^{2}=4.985 \\
p=0.083\end{array}$} \\
\hline $18.5-24.9$ & $9(6.3)$ & $21(13.2)$ & \\
\hline $25-29.9$ & $50(35.5)$ & $61(38.4)$ & \\
\hline$\geq 30$ & $82(58.2)$ & $77(48.4)$ & \\
\hline \multicolumn{3}{|l|}{ Level of education } & \multirow{5}{*}{$\begin{aligned} \chi^{2} & =24.468 \\
p & =0.000\end{aligned}$} \\
\hline I have never been educated & $26(18.5)$ & $13(8.2)$ & \\
\hline Primary school & $101(71.6)$ & $96(60.4)$ & \\
\hline High school & $14(9.9)$ & $36(22.6)$ & \\
\hline University & - & $14(8.8)$ & \\
\hline \multicolumn{3}{|l|}{ Working status } & \multirow{3}{*}{$\begin{aligned} \chi^{2} & =10.396 \\
p & =0.001\end{aligned}$} \\
\hline Working & $13(9.2)$ & $38(23.9)$ & \\
\hline Not working & $128(90.8)$ & $121(76.1)$ & \\
\hline \multicolumn{3}{|l|}{ Income perception } & \multirow{4}{*}{$\begin{aligned} \chi^{2} & =12.722 \\
p & =0.002\end{aligned}$} \\
\hline Income less than their expenses & $22(15.6)$ & $9(5.6)$ & \\
\hline Income equal to their expenses & $93(66.0)$ & $99(62.3)$ & \\
\hline Income more than their expenses & $26(18.4)$ & $51(32.1)$ & \\
\hline \multicolumn{3}{|l|}{ Marital status } & \multirow{3}{*}{$\begin{array}{l}\chi^{2}=0.025 \\
p=0.875\end{array}$} \\
\hline Married & $104(73.8)$ & $116(73.0)$ & \\
\hline Not married & $37(26.2)$ & $43(27.0)$ & \\
\hline \multicolumn{3}{|l|}{ Satisfaction with marital life } & \multirow{5}{*}{$\begin{aligned} \chi^{2} & =13.772 \\
p & =0.003\end{aligned}$} \\
\hline I am not satisfied & $16(11.4)$ & - & \\
\hline Satisfied & $50(35.5)$ & $64(40.3)$ & \\
\hline I am very pleased & $38(27.09)$ & $52(32.7)$ & \\
\hline I am not married & $37(26.2)$ & $43(27.0)$ & \\
\hline \multicolumn{3}{|l|}{ Having chronic illness } & \multirow{3}{*}{$\begin{array}{l}\chi^{2}=0.480 \\
p=0.488\end{array}$} \\
\hline Yes & $88(62.4)$ & $93(58.5)$ & \\
\hline No & $53(37.6)$ & $66(41.5)$ & \\
\hline \multicolumn{3}{|l|}{ Continuous drug use } & \multirow{3}{*}{$\begin{array}{l}\chi^{2}=0.229 \\
p=0.632\end{array}$} \\
\hline Yes & $93(66.0)$ & $109(68.6)$ & \\
\hline No & $48(34.0)$ & $50(31.4)$ & \\
\hline \multicolumn{3}{|l|}{ Smoking } & \multirow{3}{*}{$\begin{array}{l}\chi^{2}=2.181 \\
p=0.140\end{array}$} \\
\hline Yes & $27(19.1)$ & $43(27.0)$ & \\
\hline No & $114(80.9)$ & $116(73.0)$ & \\
\hline
\end{tabular}

without chronic illness, and in women with urinary incontinence it was 2.45 times higher $(p=0.000)$ than that in those without urinary incontinence (Table 4).

\section{Discussion}

Genitourinary symptoms associated with menopause and aging are usually permanent and persistent, as opposed to menopausal symptoms that disappear from time to time, such as hot flashes [1, 2, 24]. Previous studies have reported that GSM affects approximately $50 \%$ of middle-aged and elderly women [1, 2, 9-11]. Although GSM affects about half of women in the postmenopausal period, most women have no knowledge of the causes and effects of this condition.

In the present study, the incidence of GSM was higher in unemployed women with a low educational level and income. Oğurlu et al. found in their investigation 
Table 2. Comparison of gyneco-obstetric characteristics of case and control groups

\begin{tabular}{|c|c|c|c|}
\hline Gyneco-obstetric characteristics & $\begin{array}{c}\text { Case group } \\
n(\%)\end{array}$ & $\begin{array}{c}\text { Control group } \\
n(\%)\end{array}$ & $\begin{array}{l}\text { Significance } \\
\text { value }\end{array}$ \\
\hline \multicolumn{3}{|l|}{ Number of pregnancies } & \multirow{4}{*}{$\begin{aligned} \chi^{2} & =3.422 \\
p & =0.331\end{aligned}$} \\
\hline 1 & $11(7.8)$ & $10(6.3)$ & \\
\hline 2 & $12(8.5)$ & $22(13.8)$ & \\
\hline 3 and over & $118(83.7)$ & $127(79.9)$ & \\
\hline \multicolumn{3}{|l|}{ Menopause duration (years) } & \multirow{5}{*}{$\begin{array}{l}\chi^{2}=3.391 \\
p=0.335\end{array}$} \\
\hline 1 & $21(14.9)$ & $17(10.7)$ & \\
\hline 2 & $13(9.2)$ & $10(6.3)$ & \\
\hline 3 & $17(12.1)$ & $15(9.4)$ & \\
\hline 4 and over & $90(63.8)$ & $117(73.6)$ & \\
\hline \multicolumn{3}{|l|}{ Gynecologic surgery status } & \multirow{3}{*}{$\begin{array}{l}\chi^{2}=0.171 \\
p=0.680\end{array}$} \\
\hline Yes & $52(36.9)$ & $55(34.6)$ & \\
\hline No & $89(63.1)$ & $104(65.4)$ & \\
\hline \multicolumn{3}{|l|}{ Urinary incontinence } & \multirow{5}{*}{$\begin{aligned} \chi^{2} & =52.436 \\
p & =0.000\end{aligned}$} \\
\hline Never & $45(31.9)$ & $109(68.6)$ & \\
\hline Rare incontinence & $43(30.5)$ & $37(23.3)$ & \\
\hline Regular incontinence & $31(22.0)$ & - & \\
\hline Severe incontinence & $22(15.6)$ & $13(8.1)$ & \\
\hline \multicolumn{3}{|l|}{ Cause of urinary incontinence } & \multirow{6}{*}{$\begin{aligned} \chi^{2} & =52.418 \\
p & =0.000\end{aligned}$} \\
\hline Physical activity, laughing, sneezing & $25(17.7)$ & $21(13.2)$ & \\
\hline When there is a sudden urination feeling & $30(21.3)$ & $13(8.1)$ & \\
\hline In both cases & $24(17.0)$ & - & \\
\hline In situations other than these & $17(12.1)$ & $16(10.1)$ & \\
\hline I am never incontinent & $45(31.9)$ & $109(68.6)$ & \\
\hline \multicolumn{3}{|l|}{ Menopause treatment } & \multirow{3}{*}{$\begin{array}{l}\chi^{2}=1.719 \\
p=0.190\end{array}$} \\
\hline No & $123(87.2)$ & $147(92.5)$ & \\
\hline Yes (hormone replacement therapy) & $18(12.8)$ & $12(7.5)$ & \\
\hline \multicolumn{3}{|l|}{ Perception of the menopausal period } & \multirow{3}{*}{$\begin{array}{l}\chi^{2}=8.620 \\
p=0.003\end{array}$} \\
\hline Positive & $55(39.0)$ & $89(56.0)$ & \\
\hline Negative & $86(61.0)$ & $70(44.0)$ & \\
\hline
\end{tabular}

that menopause-specific urogenital problems occurred more frequently in unemployed women [25]. In the study of Çelik and Pasinlioğlu, educational level, employment status, and income status perception did not affect menopausal complaints, which was contrary to our findings [26]. Although similar in terms of sociodemographic characteristics, we believe that the results are different because the studies were conducted in different regions. Studies show that large differences both between and within cultures are influential in the perception of menopause, in terms of the menopausal behaviors and complaints in this period $[27,28]$. Therefore, to ensure the healthy well-being of postmenopausal women, the implementation of culturally appropriate mitigation and management strategies is necessary [28].

In the present study, the incidence of GSM was higher in women who were dissatisfied with their marital life. Studies have shown that women who are satisfied with their marital life have fewer menopausal complaints and a higher quality of life [26, 29-31]. The findings of the present study are comparable to those of other studies.

In the present study, the incidence of GSM was high in women who perceived menopause as negative. In Turkish society, menopause is negatively perceived by women [27, 32-34]. Yanikkerem et al. indicated that the severity of menopausal complaints is related to the attitude toward menopause [35]. Furthermore, Zivdir and Sohbet stated that the quality of life is lower in women who perceived menopause as a negative situation and feel guilty due to menopausal complaints [36]. Studies have shown that women with positive menopausal attitudes have a greater ability to cope with GSM [30, 37, 38]. The literature findings support our study. 
Table 3. Comparison of SCPS and MSQLS scores in case and control groups

\begin{tabular}{lcccc}
\hline Scales & Case group $(\mathrm{X} \pm \mathrm{SS})$ & Control group $(\mathrm{X} \pm \mathrm{SS})$ & $t$ & $p$ \\
\hline Self Care Power & $83.96 \pm 25.64$ & $101.52 \pm 21.50$ & 6.449 & 0.000 \\
\hline Menopause-Specific Living Quality & $65.52 \pm 33.47$ & $37.06 \pm 25.81$ & -8.294 & 0.000 \\
\hline Vasomotor Field & $8.01 \pm 4.65$ & $5.54 \pm 4.62$ & -4.613 & 0.000 \\
\hline Psychosocial Field & $15.09 \pm 10.49$ & $6.85 \pm 7.56$ & -7.864 & 0.000 \\
\hline Physical Field & $38.84 \pm 21.33$ & $23.11 \pm 16.40$ & -7.200 & 0.000 \\
\hline Sexual Field & $3.58 \pm 4.64$ & $1.56 \pm 3.68$ & -4.200 & 0.000 \\
\hline
\end{tabular}

Table 4. Factors associated with genitourinary syndrome (logistic regression results)

\begin{tabular}{|c|c|c|c|c|c|}
\hline Variable & $\beta$ & SE & Wald & $p$ & $\operatorname{Exp}(B)$ \\
\hline Age & -0.117 & 0.219 & 0.286 & 0.593 & 0.890 \\
\hline Working status & -0.907 & 0.479 & 3.586 & 0.058 & 0.404 \\
\hline Level of education & -0.492 & 0.173 & 8.143 & 0.004 & 0.611 \\
\hline Body mass index & 0.076 & 0.225 & 0.113 & 0.737 & 1.078 \\
\hline Income perception & 0.002 & 0.271 & 0.000 & 0.993 & 1.002 \\
\hline Marital status & -0.634 & 0.603 & 1.106 & 0.293 & 0.530 \\
\hline Satisfaction with marital life & -0.502 & 0.283 & 3.157 & 0.076 & 0.605 \\
\hline Having chronic illness & -0.821 & 0.405 & 4.119 & 0.042 & 0.440 \\
\hline Continuous drug use & 0.936 & 0.434 & 4.654 & 0.031 & 2.549 \\
\hline Smoking & -0.135 & 0.357 & 0.144 & 0.704 & 0.873 \\
\hline Number of pregnancies & -0.310 & 0.223 & 1.933 & 0.164 & 0.733 \\
\hline Menopause duration (years) & -0.204 & 0.153 & 1.784 & 0.182 & 0.815 \\
\hline Gynecologic surgery status & 0.594 & 0.311 & 3.638 & 0.056 & 1.811 \\
\hline Urinary incontinence & 0.899 & 0.179 & 25.214 & 0.000 & 2.456 \\
\hline Menopause treatment & 0.722 & 0.481 & 2.251 & 0.134 & 2.059 \\
\hline Perception of the menopausal period & 0.075 & 0.312 & 0.057 & 0.811 & 1.077 \\
\hline Constant & 3.209 & 2.691 & 1.421 & 0.233 & 24.747 \\
\hline
\end{tabular}

Model $\chi^{2}=85.051, p=0.000, R^{2}=0.330$

In the present study, the mean SCPS score was 83.96 \pm 25.64 in the case group and $101.52 \pm 21.50$ in the control group. Women living with GSM were found to have a lower self-care power. Women's lower educational level and income perception may be related to the low number of working women. In their study of postmenopausal women aged 45-55 years, Özgür et al. found a relationship among low educational level, income perception, unemployment status, and low self-care power [12]. These factors can lead to women having a lower self-care power. The continuity and progression of symptoms can also negatively affect women's self-care.

Women not living with GSM had a higher menopausal quality of life. Similar studies have shown that menopausal symptoms have negative effects on quality of life [1, 2, 9-11, 31, 39]. Nappi et al. stated that the quality of life of $52 \%$ of women in the postmenopausal period was adversely affected in terms of their sexual life, self-esteem, marriage compatibility, and social life [7]. Tohma et al. reported that vulvovaginal atrophy is a common disorder characterized by the hypoestrogen- ic state of the urogenital tissue and that irritation, dryness, painful sexual intercourse, and urinary symptoms seriously affect the quality of life of women [40]. Many studies have found that irritation, burning, dryness, and dyspareunia affect the sexual life of women, consequently decreasing quality of life [41, 42]. It is known that the symptoms of menopause affect the quality of life, and that each woman should be evaluated according to their own health status [43].

Women with a low educational level are 0.61 times more likely to have GSM than those with high levels of education. In the literature, it is stated that women with a low educational level had more menopausal complaints [21, 44, 45]. This may be attributed to the fact that women with a low educational level cannot develop effective coping strategies and are unable to receive treatment.

Genitourinary syndrome of menopause is 0.44 times more likely to occur in women with chronic disease and 2.54 times more likely in continuous drug users. Kharbound and Şahin indicate that women with chronic ill- 
ness have severe menopausal complaints [21]. This result is thought to be related to the increased risk for diseases, such as osteoporosis and cardiovascular diseases, owing to a decrease in the estrogen level and menopause.

In the present study, the incidence of GSM was 2.45 times higher in women who had urinary incontinence in a serious and sudden situation. In a study conducted with 9000 postmenopausal women in the United States, vaginal atrophy was shown to significantly correlate with other urogenital symptoms [46]. Demir ve Kızılkaya Beji stated that women who entered menopause more frequently experienced urinary incontinence, and their quality of life was affected more negatively [47]. Yilmaz et al. determined that menopause is an important risk factor for incontinence [48]. This result shows that the decrease in the estrogen level with menopause also affects the lower urinary tract, thus providing the basis for the formation of urinary incontinence.

\section{Conclusion and recommendations}

Low educational level, chronic disease, urinary incontinence, and continuous drug use have been found to be significantly associated with the occurrence of GSM. Moreover, GSM negatively affects the quality of life and self-care power of women. In line with these results:

- in the presentation of health services, women with menopausal symptoms should be evaluated for genitourinary symptoms and directed to appropriate diagnosis and treatment services;

- development and implementation of supportive programs to increase self-care power and quality of life of women and qualitative research on the subject are recommended.

\section{Ethical approval}

Prior to the investigation, approval from the ethics committee (dated November 18, 2016, approval no. 2016/003) and a hospital permit were obtained. Before starting collection of research data, women were informed about the study, and their questions were answered. Informed consent was obtained verbally. All procedures performed in studies involving human participants were in accordance with the ethical standards of the institutional and/or national research committee and with the 1964 Helsinki Declaration and its later amendments or comparable ethical standards.

\section{Disclosure}

The authors report no conflict of interest.

\section{References}

1. Portman D, Gass M; Vulvovaginal Atrophy Terminology Consensus Conference Panel. Genitourinary syndrome of menopause: new terminology for vulvovaginal atrophy from the International Society for the Study of Women's Sexual Health and the North American Menopause Society. Climacteric 2014; 17: 557-563.

2. Australasian Menopause Society (AMS). Genitourinary syndrome of menopause. Available from: http://www.menopause.org.au.

3. Simon J, Nappi R, Kingsberg S, et al. Clarifying vaginal atrophys impact on sex and relationships (CLOSER) survey: emotional and physical impact of vaginal discomfort on North American postmenopausal women and their partners. Menopause 2014; 21: 137-142.

4. Pastore L, Carter R, Hulka B, Wells E. Self-reported urogenital symptoms in postmenopausal women: women's health initiative. Maturitas 2004; 49: 292-303.

5. Calleja-Agius J, Brincat M. Urogenital atrophy. Climacteric 2009; 12: 279-285.

6. Goldstein I. Recognizing and treating urogenital atrophy in postmenopausal women. J Womens Health (Larchmt) 2010; 19: 425-432.

7. Nappi R, Kokot-Kierepa M. Vaginal health: insights, views \& attitudes (VIVA): results from an international survey. Climacteric 2012; 15: 36-44.

8. Santoro N, Komi J. Prevalence and impact of vaginal symptoms among postmenopausal women. J Sex Med 2009; 6: 2133-2142.

9. NAMS. Management of symptomatic vulvovaginal atrophy: 2013 position statement of The North American Menopause Society. Menopause 2013; 20: 888-902.

10. Nappi R, Lachowsky M. Menopause and sexuality: prevalence of symptoms and impact on quality of life. Maturitas 2009; 63: 138-141.

11. Parish S, Nappi R, Krychman M, et al. Impact of vulvovaginal health on postmenopausal women: a review of surveys on symptoms of vulvovaginal atrophy. Int J Womens Health 2013; 5: 437-447.

12. Özgür G, Yıldırım S, Komutan A. Self care agency in the postmenopausal women and effective factors. J Anadolu Nurs Health Sci 2010; 13: 35-43.

13. Turkish Statistical Institute 2011. Turkey's statistical yearbook. Available at: http://www.tuik.gov.tr (accessed 04.04.2018).

14. Turkish Statistical Institute 2013. Turkey's statistical yearbook. Available at: http://www.tuik.gov.tr (accessed 04.04.2018).

15. Panay N. Genitourinary syndrome of the menopause-dawn of a new era? Climacteric 2015; 18: 13-17.

16. Erdoğan S, Nahcivan N, Esin M. Research process, application and critics in nursing. Nobel Tıp, Ankara 2014.

17. Özerdoğan N, Beji N, Yalçın Ö. Urinary incontinence: its prevalence, risk factors and effects on the quality of life of women living in a region of Turkey. Gynecol Obstet Invest 2004; 58: 145-150.

18. Scheineder H, Heinemann L, Rosemeier H, et al. The Menapouse Rating Scale (MRS) reliability of scores of menapousal complaints. Climacteric 2000; 3: 59-64.

19. Gürkan Ö. The validity and reliability of Turkish version of menopouase rating scale. Nursing Forum 2005; 30-35.

20. Hilditch J, Lewis J, Peter A, et al. A menopause-specific quality of life questionnaire: development and psychometric properties. Maturitas 1996; 24: 161-175.

21. Kharbouch S, Şahin N. Determination of the quality of life during menopausal stages. Istanbul University Florence Nightingale School of Nursing Journal 2007; 15: 82-90.

22. Kearney B, Fleischer B. Development of an instrument to measure exercise of self-care agency. Res Nurs Health 1979; 2: 25-34.

23. Nahcivan N. Validity and reliability study: Adaptation of the self-care power scale to Turkish. Florence Nightingale Nursing Journal 1994; 7: 109-119.

24. Karakoç H, Özerdoğan N, Uçtu A. Menopause-related genitourinary syndrome. J Gynecol Obstet Neonatology 2017; 14: 122-126.

25. Oğurlu N, Küçük M, Aksu H. Influence of employment status on menopausal symptoms. Int J Gynecol Obstet 2011; 112: 204-207.

26. Çelik A, Pasinlioğlu T. Women's menopausal sypmtoms and factors affecting it during climacteric period. Hacettepe University Journal of Nursing Faculty 2014; 1: 16-29.

27. Alan S, Gozuyesil E, Gokyıldız S. Effects of menopause on the life of women who experience hot flashes and their health-seeking behaviours. Int J Caring Sci 2016; 9: 542-550. 
28. Shorey S, Ng ED. The experiences and needs of Asian women experiencing menopausal symptoms a meta-synthesis. Menopause 2018; doi: 10.1097/GME.0000000000001269.

29. Bayraktar R, Uçanok Z. Examination of menopausal approaches and intercultural studies. Family and Society Education-Culture and Research Magazine 2002; 5: 5-12.

30. Çoban A, Nehir S, Demirci H, et al. The impact on menopausal symptoms of marital adjustment and attitude toward menopausal of married women in the climacteric period. Fırat University Health Sci Med J 2008; 22: 343-349.

31. Nehir S, Çoban A, Demirci H, et al. The effect of menopausal symptoms and marital adjustment on quality of life. Cumhuriyet Med J 2009; 31: 15-21.

32. Sahin NH, Bal MD, Boga NM, et al. Women's perception of the menopause and hormone treatment: Barriers against hormone therapy. Climacteric 2011; 14: 152-156.

33. Yangin HB, Kukulu K, Sözer GA. The perception of menopause among Turkish women. J Women Aging 2010; 22: 290-305.

34. Gozuyesil E, Gokyildiz Surucu S, Alan S. Sexual function and quality-oflife-related problems during the menopausal period. J Health Psychol 2017; 1359105317742194

35. Yanıkkerem E, Koltan SO, Tamay AG, Dikayak S. Relationship between women' $s$ attitude towards menopause and quality of life. Climacteric 2012; 15: 552-562.

36. Zıvdır P, Sohbet R. Effect of feelings of guilt and shame on life quality of women in menapouse. Med Sci 2017; 12: 1-9.

37. Bloch A. Self-awerenss during the menopause. Maturitas 2002; 30 : 61-68.

38. Gharaibeh M, Al-Obeisat S, Hattab J. Severity of menopausal symptoms of Jordanian women. Climacteric 2010; 13: 385-394.

39. Nisar N, Sohoo NA. Severity of menopausal symptoms and the quality of life at different status of menopause: A community based survey from rural Sindh, Pakistan. Int J Collaborative Res Int Med Public Health 2010; 12: 118-130.

40. Tohma Y, Günakan E, Dursun P. Vulvar and vaginal atrophy. Turkiye Klinikleri J Gynecol Obst-Special Topics 2017; 10: 159-162.

41. Aba Y, Ataman H, Aytek B. New terminology in the expression of vulvovaginal atrophy: genitourinary syndrome in menopause. Andrology Bull 2016; 18: 289-293.

42. Kallak T, Baumgart J, Göransson E, et al. Aromatase inhibitors affect vaginal proliferation and steroid hormone receptors. Menopause 2014; 21: 383-390.

43. Greenblum CA, Rowe MA, Neff DF, Greenblum JS. Midlife women: symptoms associated with menopausal transition and early postmenopause and quality of life. Menopause 2013; 20: 22-27.

44. El Shafie K, Al Farsi Y, Al Zadjali N, et al. Menopausal symptoms among healthy, middle-aged Omani women as assessed with the Menopause Rating Scale. Menopause 2011; 18: 1113-1119.

45. Malacara JM, Canto de Cetina T, Bassol S, et al. Symptoms at pre- and postmenopause in rural and urban women from three states of Mexico. Maturatus 2002; 43: 11-19.

46. Constantine G, Bruyniks N, Princic N, et al. Incidence of genitourinary conditions in women with a diagnosis of vulvar/vaginal atrophy. Curr Med Res Opin 2014; 30: 143-148.

47. Demir S, Kızılkaya Beji N. Quality of life and health seeking behaviors of women with urinary incontinence. Florence Nightingale Nurs J 2015; 23 : 23-31.

48. Yılmaz E, Muslu A, Özcan E. Quality of life at women with urinary incontinence. J Erciyes University Med Sci 2014; 2: 1-14. 